\title{
Safety and Effectiveness of Dexmedetomidine in the Pediatric Intensive Care Unit (SAD-PICU)
}

\author{
Laura Carney, Jennifer Kendrick, and Roxane Carr
}

\begin{abstract}
Background: Critically ill children require sedation for comfort and to facilitate mechanical ventilation and interventions. Dexmedetomidine is a newer sedative with little safety data in pediatrics, particularly for therapy lasting longer than $48 \mathrm{~h}$.

Objective: To quantify the frequency of adverse events and withdrawal syndromes associated with dexmedetomidine and to describe the use of this drug for continuous sedation in critically ill children.
\end{abstract}

Methods: In this retrospective study of patients who received dexmedetomidine for sedation in the pediatric intensive care unit, adverse events were assessed with the Naranjo scale to determine the likelihood of association with dexmedetomidine. Interventions in response to adverse events were also recorded.

Results: One hundred and forty-four patients (median age 34 months, range $0-17.7$ years) who underwent a total of 153 treatment courses were included. The mean infusion rate of dexmedetomidine was $0.42 \mu \mathrm{g} / \mathrm{kg}$ per hour (standard deviation $0.17 \mu \mathrm{g} / \mathrm{kg}$ per hour, range $0.05-2 \mu \mathrm{g} / \mathrm{kg}$ per hour). The median duration of therapy was $20.50 \mathrm{~h}$ (range $0.75-854.75 \mathrm{~h}$ ), and 70 infusions (46\%) lasted more than $24 \mathrm{~h}$. At least one adverse event was observed in $115(75 \%)$ of the treatment courses. Hypotension (81 [53\%]) and bradycardia (38 [25\%]) were the most common adverse events and were deemed "probably" attributable to dexmedetomidine in $17(11 \%)$ and $9(6 \%)$ of the treatment courses, respectively. In 55 of the 66 treatment courses with infusions lasting longer than $24 \mathrm{~h}$ for which post-infusion data were available, at least one withdrawal symptom was observed; agitation (41 [62\%]) and hypertension (22 [33\%]) were the most common withdrawal symptoms.

Conclusions: Dexmedetomidine was commonly administered for longer than $24 \mathrm{~h}$ in the author's institution. Dexmedetomidine was generally well tolerated; however, the majority of patients experienced withdrawal symptoms. Patients receiving dexmedetomidine for more than $24 \mathrm{~h}$ should be monitored for withdrawal following discontinuation, and interventions should be provided if needed. Prospective, controlled studies are needed to characterize the safety of long-term dexmedetomidine therapy in critically ill children.

Key words: dexmedetomidine, critical care, children, sedation

Can J Hosp Pharm 2013;66(1):21-27

\section{RÉSUMÉ}

Contexte : Les enfants gravement malades ont besoin de sédation pour les soulager et faciliter la ventilation artificielle ainsi que les interventions. La dexmédétomidine est un sédatif récent pour lequel il existe peu de données sur l'innocuité de son emploi chez les enfants, particulièrement pour un traitement de plus de $48 \mathrm{~h}$.

Objectif : Quantifier la fréquence des effets indésirables et des syndromes de sevrage associés à la dexmédétomidine et décrire l'emploi de ce médicament pour la sédation continue chez les enfants gravement malades.

Méthodes : Dans le cadre de cette étude rétrospective menée chez des patients ayant reçu de la dexmédétomidine pour la sédation dans une unité de soins intensifs pédiatriques, on a évalué les effets indésirables au moyen du score de Naranjo afin de déterminer dans quelle mesure leur survenue était associée à l'emploi de la dexmédétomidine. On a également noté les interventions en réponse à un effet indésirable.

Résultats : En tout, 144 patients (âge médian de 34 mois; étendue de 0 à 17,7 ans) ayant subi un total de 153 traitements ont été inclus dans cette étude. La vitesse de perfusion moyenne de la dexmédétomidine était de $0,42 \mu \mathrm{g} / \mathrm{kg}$ par heure (écart type de $0,17 \mu \mathrm{g} / \mathrm{kg}$ par heure, étendue de 0,05 à $2 \mu \mathrm{g} / \mathrm{kg}$ par heure). La durée médiane du traitement était de $20,50 \mathrm{~h}$ (étendue de 0,75 à 854,75 h) et 70 perfusions ( $46 \%$ ) ont duré plus de $24 \mathrm{~h}$. Au moins un effet indésirable a été observé dans 115 (75\%) des traitements. L'hypotension (81 [53 \%]) et la bradycardie (38 [25\%]) étaient les effets indésirables les plus fréquents et considérées comme étant " probablement » attribuables à la dexmédétomidine respectivement dans $17(11 \%)$ et $9(6 \%)$ des traitements. Dans 55 des 66 traitements dont les perfusions ont duré plus de $24 \mathrm{~h}$ et pour lesquels on disposait de données post-perfusion, au moins un symptôme de sevrage a été observé; l'agitation (41 [62\%]) et l'hypertension (22 [33\%]) étaient les symptômes de sevrage les plus courants.

Conclusions : La dexmédétomidine est couramment administrée pour des périodes de plus de $24 \mathrm{~h}$ à l'établissement des auteurs. Elle est généralement bien tolérée; cependant, la majorité des patients éprouvent des symptômes de sevrage. L'administration de dexmédétomidine pendant plus de $24 \mathrm{~h}$ commande la surveillance des symptômes de sevrage après l'arrêt du traitement et les mesures appropriées doivent être prises au besoin. Des études prospectives comparatives sont nécessaires pour caractériser l'innocuité à long terme de la dexmédétomidine chez les enfants gravement malades.

Mots clés : dexmédétomidine, soins intensifs, enfants, sédation

[Traduction par l'éditeur] 


\section{INTRODUCTION}

Sedation is frequently required for critically ill infants and $\checkmark$ children, for comfort and to prevent self-extubation or removal of IV catheters. ${ }^{1}$ The ideal sedative agent for use in critically ill children is effective and short-acting, has a rapid onset of action, lacks active metabolites, does not accumulate in patients with renal or hepatic dysfunction, has minimal to no cardiovascular or respiratory adverse effects, and has few drug interactions. Continuous infusion of a benzodiazepine (e.g., midazolam) or an opioid (e.g., morphine) is commonly used in the critical care setting because of the sedative properties of these drugs. However, both midazolam and morphine can cause protracted sedative effects after discontinuation of infusion, are metabolized to active metabolites that would accumulate in patients with renal and hepatic dysfunction, and have multiple adverse effects (e.g., respiratory depression, hemodynamic instability, and paradoxical excitation).'

Dexmedetomidine, a newer sedative agent, is a peripheral and central $\alpha_{2}$ adrenoceptor agonist that is chemically related to clonidine. Dexmedetomidine is increasingly used in pediatric intensive care because it is short-acting (half-life of 1.6-2.5 $\mathrm{h}$ in children), has inactive metabolites, causes minimal respiratory depression, and is associated with a shorter time to extubation in children undergoing ventilation, relative to those receiving benzodiazepine infusions for sedation. ${ }^{2,3}$

Bradycardia and hypotension have often been described as significant adverse effects associated with dexmedetomidine infusions in critically ill children, but transient hypertension, respiratory depression, decreased sinus and atrioventricular node function, and nausea have also been reported. ${ }^{2-6}$ In Canada, dexmedetomidine is approved for use for up to $24 \mathrm{~h} .^{7}$ Despite this limitation on duration of therapy, reports of use exceeding $24 \mathrm{~h}$ have been published. However, data on the use of dexmedetomidine in critically ill children for periods exceeding $48 \mathrm{~h}$ are lacking. In addition, cases of withdrawal after discontinuation have been described after 3 days of dexmedetomidine therapy in critically ill children. ${ }^{6-11}$

The British Columbia Children's Hospital (BCCH) is a tertiary care pediatric centre with a 22-bed pediatric intensive care unit in Vancouver, British Columbia. Dexmedetomidine was added to this hospital's formulary in June 2010 for sedation of patients undergoing mechanical ventilation and patients with burn injuries. Because of concerns regarding the limited safety data for long-term therapy in children, the evolution of sedation therapy practice since introduction of this drug, and its higher per-unit cost relative to the established alternative sedatives, a need to review usage of this drug and patient outcomes was identified.

The primary objective of this study was to capture data on the safety of dexmedetomidine (specifically, adverse events and withdrawal syndromes) in critically ill children admitted to the Pediatric Intensive Care Unit (PICU) at the BCCH. The secondary objectives were to determine effectiveness in achieving adequate sedation and characteristics of use of dexmedetomidine (e.g., dosage, duration, patient's primary diagnosis, and comorbidities).

\section{METHODS}

Following receipt of approval from the University of British Columbia/Children's and Women's Health Centre of British Columbia Research Ethics Board, a list of all patients admitted to the PICU for whom dexmedetomidine had been prescribed between August 1, 2010, and October 1, 2011, was generated using the Department of Pharmacy's medication database. Data were collected by a single investigator (L.C.), who used a standardized case report form.

Patients less than 18 years of age for whom a dexmedetomidine infusion was initiated in the PICU were included. Patients who received dexmedetomidine for procedural sedation were excluded.

The following data were collected from each patient's medical record: age, weight, primary diagnosis, length of PICU stay, Pediatric Risk of Mortality (PRISM) score on admission, dexmedetomidine dosage and duration, presence and description of dexmedetomidine tapering schedule, adverse events, sedation and pain scores, concomitant sedatives and analgesics, number of concomitant sedative bolus doses, liver enzymes and liver function tests (i.e., baseline alanine aminotransferase, aspartate aminotransferase, and conjugated and unconjugated bilirubin, along with highest level of each recorded during treatment), presence of neurological or developmental disorders (e.g., trisomy 21, DiGeorge syndrome, seizure disorders) and other comorbidities that might affect need for or response to sedation, and use of agents that might induce or exacerbate adverse events (e.g., vasodilators, diuretics, negative inotropic agents, vasopressors, and antiarrhythmic agents). ${ }^{12}$

Bradycardia, hypotension, hypertension, emesis, neurological abnormalities, respiratory depression, hypoxia (less than $95 \%$ oxygen saturation or decrease below target determined by medical team), heart rhythm abnormalities, death, hypoglycemia, and any other adverse events that were documented in the patient record during dexmedetomidine infusion, even if not previously reported in association with dexmedetomidine, were recorded. Normal heart rate, blood pressure, respiratory rate, and blood glucose were determined on the basis of the patient's age. For all variables, an adverse event was defined as any value outside the normal range for the patient's age. ${ }^{13-15}$ The same investigator assigned a Naranjo score to every adverse event and determined the likelihood of the event being a consequence of dexmedetomidine, categorized as definite ( $\geq 9$ ), probable (5 to 8 ), possible (1 to 4 ), or doubtful 
(0) ${ }^{16}$ A second investigator (R.C.) independently calculated the Naranjo score for all events determined to have a probable or definite correlation with dexmedetomidine. If that person's score resulted in a change in classification, the third investigator (J.K.) independently evaluated the score. Interventions in response to an adverse event, if any, were also captured.

The withdrawal score, as determined with the Withdrawal Assessment Tool-1 (WAT-1), ${ }^{17}$ was recorded, along with the occurrence of potential signs and symptoms of withdrawal (any adverse signs or symptoms observed from initiation of weaning of dexmedetomidine until $72 \mathrm{~h}$ after discontinuation of infusion). If a withdrawal score was not documented in the patient's medical record, the score was estimated by the study investigator who performed the data collection, who was trained to use the scoring tools on the basis of signs and symptoms documented in physicians' and nurses' notes, as well as charting of vital signs.

The effectiveness of dexmedetomidine was evaluated by the State Behavioral Score (SBS), ${ }^{18}$ various pain scores (a visual analogue scale, the Faces Pain Scale, ${ }^{19}$ or the Multidimensional Pain Scale, ${ }^{20}$ depending on the patient's age and/or verbal ability, with all pain scores having the same numeric scale with the same interpretation), the use and dosages of concomitant sedative or analgesic infusions, and the number of bolus rescue doses of other sedative or analgesic agents. ${ }^{21}$ Sedative and analgesic agents administered for invasive procedures were not included in this analysis.

\section{Statistical Analysis}

The required sample size was determined by estimating a population proportion with specified absolute precision. ${ }^{22}$ Estimating that $10 \%$ of patients would experience an adverse event and using a confidence level of $95 \%$ and a precision of 0.05 , we determined that the sample size should be 138 treatment courses. Data were analyzed using SPSS 17.0 software (IBM, Armonk, New York). Descriptive statistics were used for demographic characteristics, concomitant sedative and analgesic use, and adverse event rates. Characteristics of dexmedetomidine administration, SBS and other pain scores, and WAT-1 scores were expressed as mean with standard deviation $(\mathrm{SD})$ or median with range, as appropriate.

\section{RESULTS}

Of the 288 patients for whom dexmedetomidine was prescribed in the 14-month study period, 201 were randomly for initial screening. Of these, 57 patients were excluded, for the following reasons: age 18 years or older $(n=4)$, no record of infusion initiation $(n=16)$, and chart incomplete or unavailable $(n=37)$. A total of 153 treatment courses for the remaining 144 patients were included in the analysis.
The primary reasons for admission to the PICU were postsurgical (mostly following cardiac surgery) and medical (Table 1). In 101 (66\%) of the treatment courses, the patient had at least one comorbidity, and in $35(23 \%)$ the patient had more than one comorbidity (Table 1 ).

The mean infusion rate for dexmedetomidine was 0.42 $\mu \mathrm{g} / \mathrm{kg}$ per hour (SD $0.17 \mu \mathrm{g} / \mathrm{kg}$ per hour), and the rate ranged from 0.05 to $2 \mu \mathrm{g} / \mathrm{kg}$ per hour (Table 2). The median duration of therapy was $20.50 \mathrm{~h}$ (range 0.75 to $854.75 \mathrm{~h}$ ), with 70 infusions (46\%) lasting longer than $24 \mathrm{~h}$ and 46 (30\%) lasting longer than $48 \mathrm{~h}$.

\section{Safety}

In 115 (75\%) of the treatment courses, at least one adverse event was reported. Hypotension and bradycardia were the 2 most frequent adverse events (Table 3). In $92(60 \%)$ of

\section{Table 1. Patient Characteristics for 153 Courses of Dexmedetomidine Therapy}

\begin{tabular}{|c|c|c|}
\hline \multirow{2}{*}{$\begin{array}{l}\text { Characteristic } \\
\text { Age (months), median (range) }\end{array}$} & \multicolumn{2}{|c|}{$\begin{array}{c}\text { No. }(\%) \text { of } \\
\text { Treatment Courses* } \\
(n=153)\end{array}$} \\
\hline & 34 & $(0-212)$ \\
\hline Weight (kg), median (range) & 15 & $(2.4-79)$ \\
\hline Female, no. (\%) & 58 & (38) \\
\hline Length of stay (days), median (range) & 4 & $(1-111)$ \\
\hline PRISM score, median (range) & 3 & $(0-31)$ \\
\hline \multicolumn{3}{|l|}{ Primary diagnosis } \\
\hline Postsurgical, cardiac & 62 & $(41)$ \\
\hline Postsurgical, noncardiac & 31 & (20) \\
\hline Respiratory infection & 13 & (8) \\
\hline Burn & 5 & (3) \\
\hline Sepsis & 5 & (3) \\
\hline Other infection & 5 & (3) \\
\hline Brain injury & 4 & (3) \\
\hline Other & 28 & $(18)$ \\
\hline \multicolumn{3}{|l|}{ Comorbidities† } \\
\hline Congenital heart defect & 66 & $(43)$ \\
\hline Seizure disorder & 18 & $(12)$ \\
\hline Trisomy 21 & 8 & (5) \\
\hline Renal impairment & 5 & (3) \\
\hline Heart failure & 5 & (3) \\
\hline Chronic apnea or lung disease & 4 & (3) \\
\hline Gastrointestinal disorder & 4 & (3) \\
\hline Arrhythmia & 3 & (2) \\
\hline q22 deletion & 3 & (2) \\
\hline Chronic hypertension & 2 & (1) \\
\hline Endocrine disorder & 2 & (1) \\
\hline Other & 20 & (13) \\
\hline None & 52 & (34) \\
\hline
\end{tabular}

PRISM = Pediatric Risk of Mortality.

*Except where indicated otherwise. Treatment was provided to 144 patients, some of whom had more than one course of therapy. Characteristics are presented in relation to the number of courses of therapy.

tSome patients had more than one comorbidity. 
Table 2. Dexmedetomidine Usage by Age at Time of Infusion

\begin{tabular}{|c|c|c|c|}
\hline Age Group* & $\begin{array}{c}\text { Mean dosage (SD) } \\
\text { ( } \mu \mathrm{g} / \mathrm{kg} \text { per hour) }\end{array}$ & $\begin{array}{l}\text { Dosage range } \\
\text { ( } \mu \mathrm{g} / \mathrm{kg} \text { per hour) }\end{array}$ & $\begin{array}{l}\text { Median duration } \\
\text { (range) (h) }\end{array}$ \\
\hline$\overline{\text { All }(n=153)}$ & $0.42 \quad(0.17)$ & $0.05-2$ & $20.50(0.75-854.75)$ \\
\hline$\leq 1 \mathrm{mo}(n=19)$ & $0.34 \quad(0.13)$ & $0.1-0.7$ & $40.75 \quad(9.00-307.00)$ \\
\hline$>1 \mathrm{mo}$ to $1 \mathrm{yr}(n=38)$ & $0.43 \quad(0.10)$ & $0.1-1$ & $37.50(0.75-263.00)$ \\
\hline$>1 \mathrm{yr}$ to $5 \mathrm{yr}(n=24)$ & $0.52 \quad(0.25)$ & $0.1-2$ & $23.63(7.00-854.75)$ \\
\hline$>5 \mathrm{yr}$ to $12 \mathrm{yr}(n=37)$ & $0.43 \quad(0.15)$ & $0.05-1$ & $17.50(1.00-653.50)$ \\
\hline$>12$ yr $(n=35)$ & $0.37 \quad(0.15)$ & $0.05-0.8$ & $19.50(1.00-216.00)$ \\
\hline
\end{tabular}

$\mathrm{SD}=$ standard deviation.

*Data were analyzed in terms of the number of courses of therapy $(n=153)$.

Table 3. Frequency of at Least One Adverse Effect by Age at Time of Infusion

No. (\%) of Infusions*

\begin{tabular}{|c|c|c|c|c|c|c|c|c|c|c|c|c|}
\hline \multirow{2}{*}{$\begin{array}{l}\text { Adverse Event } \\
\text { Hypotension }\end{array}$} & \multicolumn{2}{|c|}{$\begin{array}{c}\text { All } \\
(n=153)\end{array}$} & \multicolumn{2}{|c|}{$\begin{array}{l}\leq 1 \mathrm{mo} \\
(n=19)\end{array}$} & \multicolumn{2}{|c|}{$\begin{array}{c}>1 \mathrm{mo} \text { to } 1 \mathrm{yr} \\
(n=38)\end{array}$} & \multicolumn{2}{|c|}{$\begin{array}{c}>1 \mathrm{yr} \text { to } 5 \mathrm{yr} \\
(n=24)\end{array}$} & \multicolumn{2}{|c|}{$\begin{array}{c}>5 \mathrm{yr} \text { to } 12 \mathrm{yr} \\
(n=37)\end{array}$} & \multicolumn{2}{|c|}{$\begin{array}{l}>12 y \\
(n=35)\end{array}$} \\
\hline & 81 & (53) & 17 & (89) & 17 & (45) & 7 & (29) & 15 & (41) & 25 & (71) \\
\hline Bradycardia & 38 & (25) & 4 & (21) & 18 & (47) & 4 & (17) & 8 & (22) & 4 & (11) \\
\hline Hypertension & 14 & (9) & 0 & & 0 & & 5 & (21) & 3 & (8) & 6 & (17) \\
\hline Emesis & 14 & (9) & 1 & (5) & 4 & (11) & 0 & & 5 & (14) & 4 & (11) \\
\hline $\begin{array}{l}\text { Respiratory } \\
\text { depression }\end{array}$ & 8 & (5) & 0 & & 3 & (8) & 1 & (4) & 2 & (5) & 2 & (6) \\
\hline Arrhythmia & 4 & (3) & 1 & (5) & 1 & (3) & 0 & & 2 & (5) & 0 & \\
\hline Othert & 9 & (6) & 0 & & 3 & (8) & 1 & (4) & 3 & (8) & 2 & (6) \\
\hline
\end{tabular}

*Some patients had more than one adverse event.

tOther adverse events reported: seizure (3 events), status epilepticus, hallucinations, mydriasis, asystole, nausea, diarrhea.

the infusions, the patient received at least one concomitant vasoactive or negative inotropic medication. Hypotension and bradycardia were deemed "probably" attributable to dexmedetomidine (with a Naranjo score of 5 to 8 ) in 17 (11\%) and $9(6 \%)$ of the treatment courses, respectively. The remainder of the adverse events had a Naranjo score of 4 or below (i.e., possible or doubtful association). Some adverse events occurred more than once during a given treatment course, and some patients underwent multiple interventions during a single treatment. Forty-six (52\%) of the 89 bradycardia events required an intervention, as did 114 (59\%) of the 193 hypotension events, $6(40 \%)$ of the 15 hypertension events, 6 (21\%) of the 28 emesis events, $5(62 \%)$ of the 8 respiratory depression events, 2 (25\%) of the 8 arrhythmia events, and $6(27 \%)$ of the 22 other events.

The adverse event rate was also analyzed by duration of dexmedetomidine treatment (infusions lasting longer than $48 \mathrm{~h}$ [ $n=46]$ compared with those lasting up to $48 \mathrm{~h}[n=107])$ (Table 4). Hypotension events with a Naranjo score indicative of a possible association (i.e., score of 5 to 8) with dexmedetomidine were observed for $11(24 \%)$ of the infusions lasting longer than $48 \mathrm{~h}$ and $6(6 \%)$ of those lasting $48 \mathrm{~h}$ or less. Bradycardia events with a Naranjo score indicative of a possible association occurred for 4 (9\%) of the infusions lasting longer than $48 \mathrm{~h}$ and 5 (5\%) of those lasting up to $48 \mathrm{~h}$. Death was reported in 2 cases but was related to the patient's underlying disease, as determined by physicians documentation in the medical record.

\section{Effectiveness}

The proportion of SBS scores that were within the target range for sedation in the PICU ( -1 to 0 ) was $65 \%$ (1150/1762); 3\% (54/1762) of the SBS scores signified oversedation and 32\% (558/1762) signified undersedation). The proportion of pain scores within target range ( 2 or below out of 10) was $79 \%(1385 / 1762)$. The use of concomitant medications with sedative and analgesic properties is described in Table 5. In $66(43 \%)$ of the infusions, 2 or more sedatives were administered in addition to dexmedetomidine.

\section{Withdrawal}

Of the 66 infusions with a duration greater than 24 hours and with data after initiation of dexmedetomidine tapering, 55 $(83 \%)$ had at least one sign of withdrawal and $33(50 \%)$ had at least 2 signs. Of these 66 infusions, the most common sign of withdrawal was agitation, occurring after $41(62 \%)$ infusions. Hypertension occurred in 22 (33\%), vomiting in $16(24 \%)$, diarrhea in $16(24 \%)$, anxiety in $7(11 \%)$, seizure in $1(2 \%)$, and other signs potentially attributable to withdrawal (abdominal cramping, tachycardia, tremors, back arching, side-to-side head movement, yawning) in $4(6 \%)$. The median peak 
Table 4. Frequency of At Least One Adverse Event by Duration of Treatment Course

No. (\%) of Infusions

\begin{tabular}{|c|c|c|c|c|}
\hline Adverse Event & $\begin{array}{r}\text { Infusi } \\
\text { (n }\end{array}$ & $\begin{array}{l}n \leq 48 h \\
107)\end{array}$ & $\begin{array}{r}\text { Infusi } \\
(n\end{array}$ & $\begin{array}{l}\text { h > } 48 h \\
=46)\end{array}$ \\
\hline Hypotension & 47 & (44) & 34 & $(74)$ \\
\hline Bradycardia & 23 & (21) & 15 & (33) \\
\hline Hypertension & 9 & (8) & 5 & $(11)$ \\
\hline Emesis & 8 & (7) & 6 & $(13)$ \\
\hline Respiratory depression & 8 & (7) & 0 & \\
\hline Arrhythmia & 2 & $(2)$ & 2 & (4) \\
\hline Other* & 3 & (3) & 6 & (13) \\
\hline
\end{tabular}

*Other adverse events reported: seizure (3 events), status epilepticus, hallucinations, mydriasis, asystole, nausea, diarrhea.

Table 5. Concomitant Use of Sedative or Analgesic

\begin{tabular}{lrc} 
Medication & $\begin{array}{r}\text { No. (\%) of Infusions } \\
(\boldsymbol{n}=\mathbf{1 5 3})\end{array}$ \\
\hline Opioid & 127 & $(83)$ \\
Midazolam & 41 & $(27)$ \\
Chloral hydrate & 36 & $(24)$ \\
Propofol & 15 & $(10)$ \\
Lorazepam & 12 & $(8)$ \\
Ketamine & 9 & $(6)$ \\
Clonidine & 3 & $(2)$ \\
Methotrimeprazine & 2 & $(1)$ \\
Gabapentin & 1 & $(1)$ \\
None & 14 & $(9)$ \\
\hline
\end{tabular}

WAT-1 score was 1 (range $0-10$ ), but only 1 patient experienced WAT-1 scores greater than 3 (which would be indicative of withdrawal).

Sixty treatment courses lasting more than $24 \mathrm{~h}$ had data regarding both withdrawal symptoms and presence of concomitant sedative use during dexmedetomidine weaning and after discontinuation. Of the 50 treatment courses in this group in which the patient experienced at least one potential withdrawal sign, 39 (78\%) involved at least one concomitant sedative at some point during the withdrawal observation period. Of the 10 treatment courses in which no potential withdrawal signs were experienced, $6(60 \%)$ involved a least one concomitant sedative in the same period.

\section{DISCUSSION}

This retrospective analysis describes the use of dexmedetomidine in critically ill children at the authors' institution. Although a substantial proportion of the included patients had undergone cardiac surgery, there was diversity in patient age, comorbidities, and primary diagnosis. The dosages observed were in alignment with the recommendations in the institution's dosing handbook and what has been reported in previous reviews of dexmedetomidine use in the pediatric critical care setting. ${ }^{4-6,13,23}$ The median duration of infusion was less than $24 \mathrm{~h}$, but a large group of patients received the drug for longer than $48 \mathrm{~h}$.

Similar to other studies in critically ill children, ${ }^{3,4,6,24}$ the adverse event profile of dexmedetomidine in this study consisted mainly of hemodynamic effects: bradycardia, hypotension, and transient hypertension. By using the Naranjo scale, a validated scoring system for determining the causality of adverse events in relation to medications, we determined that in only a fraction of the 153 treatment courses could bradycardia (6\%) and hypotension (11\%) "probably" be attributed to dexmedetomidine. The Naranjo scale takes into account the temporal relation between the adverse event and administration of the medication, the presence of objective evidence for the relationship, reproducibility of the event, and presence of alternative causes, as well as success of interventions. In a smaller retrospective study of dexmedetomidine in critically ill children, bradycardia occurred in $15 \%$ of infusions and hypotension in $22 \%$. $^{6}$ Similar reviews have reported bradycardia or hypotension occurring in $21 \%$ to $27 \%$ of patients. ${ }^{3,4}$ Other studies have described no clinically significant change in hemodynamic parameters. $^{23,25,26}$

Although some patients experienced respiratory depression during dexmedetomidine therapy, the Naranjo scale score for these events was insufficient to determine dexmedetomidine as a definite or probable cause. This situation is consistent with the findings of previous studies, which have reported little or no respiratory depression with dexmedetomidine, a significant consequence of available alternative sedatives such as midazolam. ${ }^{3,13}$ Other adverse events reported (emesis, arrhythmia, hypertension, seizures, hallucinations, and mydriasis) also did not appear to be more than "possibly" caused by dexmedetomidine, according to the Naranjo scale.

The adverse event rates during infusions longer than $48 \mathrm{~h}$ were consistently higher than those lasting $48 \mathrm{~h}$ or less. There 
were also higher rates of hypotension and bradycardia deemed probably attributable to dexmedetomidine in the treatment courses lasting longer than $48 \mathrm{~h}$. These results, while not statistically validated, imply that continual monitoring for adverse events is required during prolonged infusions and that tolerance to the hemodynamic effects of dexmedetomidine may be unlikely.

The use of other sedatives was common in this study population. The prevalent use of opioids was likely attributable to their analgesic as well as sedative properties. However, in $43 \%$ of the infusions, 2 or more medications with sedative properties were used in addition to dexmedetomidine. Despite the substantial use of adjunctive sedatives, almost a third of sedation evaluation scores were above target range (indicating undersedation). This result contradicts earlier findings in smaller pediatric critical care studies, which indicated that dexmedetomidine was associated with adequate sedation in greater than $90 \%$ of cases. ${ }^{3,24,27}$ However, investigators in previous studies used different methods of evaluating sedation, for example, using alternative evaluation tools or counting the number of rescue bolus doses. In addition, lack of familiarity with dexmedetomidine, especially immediately after its addition to the hospital formulary, may have led to less than optimal use.

Withdrawal symptoms were evident in this study. Agitation, hypertension, vomiting, and diarrhea were the most common adverse events occurring within $72 \mathrm{~h}$ after discontinuation of dexmedetomidine. However, a substantial proportion of patients were also receiving other sedatives, which were often being weaned or manipulated simultaneously. In such a setting, the withdrawal symptoms of other sedatives may have been falsely attributed to dexmedetomidine. Despite the presence of withdrawal signs and symptoms, the WAT-1 scores observed were not consistent with withdrawal. The WAT-1 tool has been validated for use in assessing opioid and benzodiazepine withdrawal, which limits its applicability in assessing and quantifying the severity of dexmedetomidine withdrawal. However, since there is no validated tool to evaluate dexmedetomidine withdrawal, the WAT-1 tool was used in this study. According to case reports, dexmedetomidine withdrawal may have some similarities to opioid and benzodiazepine withdrawal (e.g., agitation, anxiety), but it may also manifest as tachycardia and hypertension..$^{8-10}$ In a recent retrospective case series, Burbano and others ${ }^{28}$ investigated the frequency of dexmedetomidine withdrawal symptoms in patients in the PICU up to $12 \mathrm{~h}$ after discontinuation of the infusion (median duration of infusion 5.8 days, range 4-26 days). They found that transient hypertension occurred in $35 \%$ of the patients, tachycardia in $27 \%$, and agitation in $27 \%$. However, the proportion of patients who were simultaneously being weaned off additional sedatives was not reported. ${ }^{28}$

In the current study, the majority of treatment courses longer than $24 \mathrm{~h}$ were accompanied, at some point, by at least one concomitant sedative during the tapering of dexmedetomidine and within $72 \mathrm{~h}$ after its discontinuation. However, the use of concomitant sedatives did not appear to affect the rate of signs of withdrawal. This outcome could be due to the practice, in this institution, of weaning all sedatives simultaneously.

Our study had limitations, some of which were due to its retrospective design. The precision of adverse event frequency was affected by reporting bias in the medical records. SBS and pain scores were typically reported at least every $6 \mathrm{~h}$ but did have to be estimated in a minority of cases by one of the investigators. WAT-1 scores were recorded for only one patient; all other WAT-1 scores were estimated from data in the medical record. This situation further limits the applicability of the WAT-1 score in evaluating the true extent of dexmedetomidine withdrawal. For consistency, only one investigator estimated these scores, the same person who determined the Naranjo scores. Adverse events were largely hemodynamic in nature and, for objectivity, were mainly defined according to accepted limits for patient age, as opposed to individualized physiciandefined targets. The exception to this approach was the oxygen saturation targets, which often had a physician-defined target range of less than $95 \%$ in patients who had undergone cardiac surgery.

If dexmedetomidine is to be used as an alternative sedative to benzodiazepines, further randomized controlled studies on its effectiveness and safety are required. A recent Canadian economic comparison of dexmedetomidine and midazolam in critically ill adult patients concluded that although acquisition costs for dexmedetomidine are higher than those for midazolam, the decreased need for mechanical ventilation and delirium management with dexmedetomidine make this drug less costly overall. ${ }^{29}$ Given the high frequency of withdrawal symptoms in our study and others, further research into the optimal method of dexmedetomidine discontinuation in critically ill infants and children is also warranted, as well as the long-term, particularly developmental, effects of its use in the pediatric population.

\section{CONCLUSIONS}

This chart review has provided further data about the use of dexmedetomidine in a diverse mix of medical and surgical pediatric patients in the PICU. Hemodynamic adverse events such as hypotension and bradycardia were common and increased in frequency with longer duration of infusion. This trend should be considered when evaluating the risks and benefits of extending infusion beyond $48 \mathrm{~h}$. Patients should be monitored for withdrawal symptoms such as agitation and hypertension after discontinuation of dexmedetomidine infusion. Most patients had adequate sedation while receiving dexmedetomidine, and fewer than half of infusions were given with 2 or more additional sedative or analgesic agents. 


\section{References}

1. Playfor S, Jenkins I, Boyles C, Choonara I, Davies G, Haywood T, et al.; United Kingdom Paediatric Intensive Care Society, Sedation, Analgesia and Neuromuscular Blockade Working Group. Consensus guidelines on sedation and analgesia in critically ill children. Intensive Care Med. 2006;32(8):1125-36.

2. Su F, Hammer GB. Dexmedetomidine: pediatric pharmacology, clinical uses and safety. Expert Opin Drug Saf. 2011;10(1):55-66.

3. Hosokawa K, Shime N, Kato Y, Taniguchi A, Maeda Y, Miyazaki T, et al. Dexmedetomidine sedation in children after cardiac surgery. Pediatr Crit Care Med. 2010;11(1):39-43.

4. Czaja AS, Zimmerman JJ. The use of dexmedetomidine in critically ill children. Pediatr Crit Care Med. 2009;10(3):381-6.

5. Lazol JP, Lichtenstein SE, Jooste EH, Shiderly D, Kudchadker NA, Tatum $\mathrm{GH}$, et al. Effect of dexmedetomidine on pulmonary artery pressure after congenital cardiac surgery: a pilot study. Pediatr Crit Care Med. 2010;11(5):589-92.

6. Honey BL, Harrison DL, Gormley AK, Johnson PN. Evaluation of adverse events noted in children receiving continuous infusions of dexmedetomidine in the intensive care unit. J Pediatr Pharmacol Ther. 2010;15(1):30-7.

7. Precedex. In: Repchinsky C, editor. Compendium of pharmaceuticals and specialties 2011. Ottawa (ON): Canadian Pharmacists Association; 2011 [cited 2011 Jul 16]. Available from: https:/www.e-therapeutics.ca/. Subscription required to access content.

8. Darnell C, Steiner J, Szmuk P, Sheeran P. Withdrawal from multiple sedative agent therapy in an infant: Is dexmedetomidine the cause or the cure? Pediatr Crit Care Med. 2010;11(1):e1-3.

9. Tobias JD. Dexmedetomidine: Are tolerance and withdrawal going to be an issue with long-term infusions? Pediatr Crit Care Med. 2010;11(1):158-60.

10. Weber MD, Thammasitboon S, Rosen DA. Acute discontinuation syndrome from dexmedetomidine after protracted use in a pediatric patient. Paediatr Anaesth. 2008;18(1):87-8.

11. Enomoto Y, Kudo T, Saito T, Hori T, Kaneko M, Matsui A, et al. Prolonged use of dexmedetomidine in an infant with respiratory failure following living donor liver transplantation. Paediatr Anaesth. 2006; 16(12):1285-8.

12. Pollack MM, Ruttimann UE, Getson PR. Pediatric risk of mortality (PRISM) score. Crit Care Med. 1988;16(11):1110-6.

13. Taketomo CK, Hodding JH, Kraus DM, editors. Pediatric dosage handbook. 17th ed. Hudson (OH): Lexi-Comp Inc; 2009.

14. Custer JW, Rau RE, editors. The Harriet Lane handbook. 18th ed. Philadelphia (PA): Elsevier Inc; 2009.

15. ECC Committee, Subcommittees and Task Forces of the American Heart Association. 2005 American Heart Association guidelines for cardiopulmonary resuscitation and emergency cardiovascular care. Circulation. 2005;112(24 Suppl):IV1-167.

16. Naranjo CA, Busto U, Sellers EM, Sandor P, Ruiz I, Roberts EA, et al. A method for estimating the probability of adverse drug reactions. Clin Pharmacol Ther. 1981;30(2):239-45.

17. Franck LS, Harris SK, Soetenga DJ, Amling JK, Curley MA.. The Withdrawal Assessment Tool-1 (WAT-1): an assessment instrument for monitoring opioid and benzodiazepine withdrawal symptoms in pediatric patients. Pediatr Crit Care Med. 2008;9(6):573-80.

18. Curley MAQ, Harris SK, Fraser KA, Johnson RA, Arnold JH. State Behavioral Scale: a sedation assessment instrument for infants and young children supported on mechanical ventilation. Pediatr Crit Care Med. 2006;7(2):107-14.
19. Hicks CL, von Baeyer CL, Spafford PA, van Korlaar I, Goodenough B. The Faces Pain Scale-Revised: toward a common metric in pediatric pain measurement. Pain. 2001;93(2):173-83.

20. Ramelet AS, Rees NW, McDonald S, Bulsara MK, Huijer Abu-Saad H. Clinical validation of the Multidimensional Assessment of Pain Scale. Paediatr Anaesthes. 2007;17(12):1156-65.

21. Abu-Saad H. Assessing children's responses to pain. Pain. 1984;19(2):163-71.

22. Lwanga SK, Lemeshow S. Sample size determination in health studies: a practical manual. Geneva (Switzerland): World Health Organization; 1991.

23. Bejian S, Valasek C, Nigro JJ, Cleveland DC, Willis BC. Prolonged use of dexmedetomidine in the paediatric cardiothoracic intensive care unit. Cardiol Young. 2009;19(1):98-104.

24. Chrysostomou C, Di Filippo S, Manrique AM, Schmitt CG, Orr RA, Casta A, et al. Use of dexmedetomidine in children after cardiac and thoracic surgery. Pediatr Crit Care Med. 2006;7(2):126-31.

25. Tobias JD, Berkenbosch JW. Sedation during mechanical ventilation in infants and children: dexmedetomidine versus midazolam. South Med J. 2004;97(5):451-5.

26. Buck ML, Willson DF. Use of dexmedetomidine in the pediatric intensive care unit. Pharmacotherapy. 2008;28(1):51-7.

27. Walker J, MacCallum M, Fischer C, Kopcha R, Saylors R, McCall J. Sedation using dexmedetomidine in pediatric burn patients. J Burn Care Res. 2006;27(2):206-10.

28. Burbano NH, Otero AV, Berry DE, Orr RA, Munoz RA. Discontinuation of prolonged infusions of dexmedetomidine in critically ill children with heart disease. Intensive Care Med. 2012;38(2):300-7.

29. Lachaine J, Beauchemin C. Economic evaluation of dexmedetomidine relative to midazolam for sedation in the intensive care unit. Can J Hosp Pharm. 2012;65(2):103-10.

Laura Carney, BSc(Pharm), ACPR, is with the Department of Pharmacy, Children's and Women's Health Centre of British Columbia, Vancouver, British Columbia.

Jennifer Kendrick, BSC(Pharm), ACPR, PharmD, was, at time this study was conducted, with the Children's and Women's Health Centre of British Columbia. She is now with the Department of Pharmacy, St Paul's Hospital, Vancouver, British Columbia.

Roxane Carr, BSC(Pharm), ACPR, PharmD, FCSHP, BCPS, is with the Department of Pharmacy, Children's and Women's Health Centre of British Columbia and the Faculty of Pharmaceutical Sciences, University of British Columbia, Vancouver, British Columbia.

Competing interests: Roxane Carr has received a speaker's fee from the BC Branch of the Canadian Society of Hospital Pharmacy for a presentation on a related topic.

\section{Address correspondence to:}

Dr Roxane Carr

Pharmacy

Children's and Women's Health Centre of British Columbia

4500 Oak Street, Room OB7

Vancouver BC V6H 3N1

e-mail: rcarr@cw.bc.ca 